\title{
Identification of 3,3'-O-dimethylellagic acid and apigenin as the main antiplasmodial constituents of Endodesmia calophylloides Benth and Hymenostegia afzelii (Oliver.) Harms
}

Rodrigue Keumoe ${ }^{1,2}$, Jean Garba Koffi ${ }^{3}$, Darline Dize ${ }^{1}$, Patrick Valère Tsouh Fokou', Joseph Tchamgoue ${ }^{3}$, Lawrence Ayong ${ }^{2}$, Bruno Lenta Ndjakou ${ }^{3}$, Norbert Sewald ${ }^{4}$, Bathelemy Ngameni ${ }^{5}$ and Fabrice Fekam Boyom ${ }^{1 *}$

\begin{abstract}
Background: Endodesmia calophylloides and Hymenostegia afzelii belong to the Guttiferae and Caesalpiniaceae plant families with known uses in African ethno-medicine to treat malaria and several other diseases. This study aimed at identifying antiplasmodial natural products from selected crude extracts from $\mathrm{H}$. afzelii and $\mathrm{E}$. calophylloides and to assess their cytotoxicity.

Methods: The extracts from H. afzelii and E. calophylloides were subjected to bioassay-guided fractionation to identify antiplasmodial compounds. The hydroethanol and methanol stem bark crude extracts, fractions and isolated compounds were assessed for antiplasmodial activity against the chloroquine-sensitive 3D7 and multi-drug resistant Dd2 strains of Plasmodium falciparum using the SYBR green I fluorescence-based microdilution assay. Cytotoxicity of active extracts, fractions and compounds was determined on African green monkey normal kidney Vero and murine macrophage Raw 264.7 cell lines using the Resazurin-based viability assay.

Results: The hydroethanolic extract of $\mathrm{H}$. afzelii stem bark (Hasb ${ }^{\mathrm{HE}}$ ) and the methanolic extract of E. calophylloides stem bark (Ecsb ${ }^{\mathrm{M}}$ ) exhibited the highest potency against both $P f 3 D 7$ ( $E C_{50}$ values of $3.32 \pm 0.15 \mu \mathrm{g} / \mathrm{mL}$ and $7.40 \pm$ $0.19 \mu \mathrm{g} / \mathrm{mL}$, respectively) and PfDd2 ( $E_{50}$ of $3.08 \pm 0.21 \mu \mathrm{g} / \mathrm{mL}$ and $7.48 \pm 0.07 \mu \mathrm{g} / \mathrm{mL}$, respectively) strains. Both extracts showed high selectivity toward Plasmodium parasites $(\mathrm{SI}>13)$. The biological activity-guided fractionation led to the identification of five compounds (Compounds 1-5) from Hasb ${ }^{\mathrm{HE}}$ and one compound (Compound 6) from $\mathrm{Ecsb}^{\mathrm{M}}$. Of these, Compound 1 corresponding to apigenin ( $\mathrm{EC}_{50}$ Pf3D7, of $19.01 \pm 0.72 \mu \mathrm{M}$ and $\mathrm{EC}_{50}$ PfDd2 of $16.39 \pm 0.52 \mu \mathrm{M})$, and Compound 6 corresponding to 3,3'-O-dimethylellagic acid ( $E C_{50}$ Pf3D7 of $4.27 \pm 0.05 \mu \mathrm{M}$ and $\mathrm{EC}_{50}$ PfDd2 of $1.36 \pm 0.47 \mu \mathrm{M}$ ) displayed the highest antiplasmodial activities. Interestingly, both compounds exhibited negligible cytotoxicity against both Vero and Raw 264.7 cell lines with selectivity indices greater than 9.
\end{abstract}

\footnotetext{
* Correspondence: fabrice.boyom@fulbrightmail.org

${ }^{1}$ Antimicrobial and Biocontrol Agents Unit (AmBcAU), Laboratory for Phytobiochemistry and Medicinal Plants Studies, Department of

Biochemistry, Faculty of Science, University of Yaoundé I, P.O. Box 812,

Yaoundé, Cameroon

Full list of author information is available at the end of the article
}

(c) The Author(s). 2021 Open Access This article is licensed under a Creative Commons Attribution 4.0 International License, which permits use, sharing, adaptation, distribution and reproduction in any medium or format, as long as you give appropriate credit to the original author(s) and the source, provide a link to the Creative Commons licence, and indicate if changes were made. The images or other third party material in this article are included in the article's Creative Commons licence, unless indicated otherwise in a credit line to the material. If material is not included in the article's Creative Commons licence and your intended use is not permitted by statutory regulation or exceeds the permitted use, you will need to obtain permission directly from the copyright holder. To view a copy of this licence, visit http://creativecommons.org/licenses/by/4.0/. The Creative Commons Public Domain Dedication waiver (http://creativecommons.org/publicdomain/zero/1.0/) applies to the data made available in this article, unless otherwise stated in a credit line to the data. 
Conclusions: This study led to the identification of two potent antiplasmodial natural compounds, 3,3'-Odimethylellagic acid and apigenin that could serve as starting points for further antimalarial drug discovery.

Keywords: 3,3'-O-dimethylellagic acid, Apigenin, Antiplasmodial activity, Bioguided fractionation

\section{Background}

Malaria is a mosquito-borne disease caused by protozoan parasites belonging to the genus Plasmodium. At least five Plasmodium species are known to cause malaria in humans, the deadliest of which is Plasmodium falciparum. Despite substantial global efforts towards its eradication, malaria remains a major public health problem, particularly in sub-Saharan Africa. According to the World Health Organization (WHO), an estimated 228 million cases and 405,000 deaths due to malaria occurred in 2018, with the Sub-Saharan African regions accounting for over $94 \%$ of the global mortality [1].

In the absence of vaccines with operational utility against malaria, accurate diagnosis and effective treatment remain the best hope of averting severe complications of the disease. Several antimalarial drugs including mefloquine, chloroquine, quinine, proguanil, atovaquone, sulphadoxine-pyrimethamine and artemisinin were developed for this purpose. However, rapid development of $P$. falciparum parasites resistance to such excepting artemisinin appeared [2]. The WHO therefore recommended the artemisinin-based combination therapies (ACTs) as first line antimalarial treatment since 2006 [3]. In the ACTs, the fast and short acting artemisinin is combined with long acting partners to exert improved effect against malaria parasites $[4,5]$. Nevertheless, the ACTs are currently facing increasing threat of widespread $P$. falciparum resistance as delayed parasite clearance has been reported in South East Asia and Africa [6-8]. In addition, drug toxicity and high cost are associated with compliance issues to limit access and completion of malaria treatment in high-burdened settings. Overall, several challenges exist in the chemotherapy of malaria, and include widespread resistance and the limited number of drug choices available to manage multidrugresistant parasite strains. To address these challenges, the antimalarial drug discovery pipeline should be continuously flushed-in with novel chemical scaffolds having promising features as starting points for new drugs development to combat malaria. One of the approaches to achieve this goal is to investigate herbal medicines and their derived secondary metabolites.

Historically, plants have played remarkable roles in antimalarial drug discovery, and they continue to serve as principal sources of new antimalarial therapies. Of note, the antimalarials, quinine and artemisinin are illustrative examples isolated from the barks of Cinchona species and leaves of Artemisia annua L., respectively $[9,10]$. It is of common knowledge that the historical ethnomedicinal practices while using these plants to cure malaria further guided the isolation procedures of their active principles (quinine and artemisinin). Indeed, the bark of the Cinchona tree native to South America provides a rich source of medicinal alkaloids. The first use of the bark in treating malaria is often attributed to Jesuit missionaries in seventeenth century in Peru, though the indigenous population used hot infusions of the bark much earlier to combat shivering in cold and damp conditions. In the case of Artemisia annua L., the Chinese medicine indicated that "one bunch of qinghao (dried aerial part of Artemisia annua L.) in two sheng of water was mashed and the juice administered to patients." Given the vast floristic diversity of Cameroon which is widely explored by indigenous population for the treatment of various illnesses including malaria, $H$. afzelii and E. calophylloides were selected for this study based on their ethnobotanical importance and the gap in their scientific exploration.

Hymenostegia afzelii and E. calophylloides belong respectively to Caesalpiniaceae and Guttiferae plant families that are broadly distributed in Cameroon. Species from these plant families are widely used in African folk medicine for the treatment of several illnesses including malaria [11-14]. Of note, $H$. afzelii is used in African traditional medicine to treat various diseases. A decoction of leaves and roots is used in Ghana to treat cough and whooping cough and wounds. The twigs are used throughout west Africa as chewing sticks to clean teeth $[11,12,15]$. Endodesmia calophylloides, the sole species in the Endodesmia genus is also used in folk medicine to heal filariasis and diarrhea, and as eye-instillation [16, 17]. Though a single report has mentioned the antiplasmodial activity of extracts from E. calophylloides [18], the potential of $H$. afzelii extracts against malaria parasites remains to be documented. The present paper reports the bioassay-guided isolation of two antiplasmodial compounds, apigenin (1) and 3,3'-O-dimethylellagic acid (6) from $H$. afzelii and E. calophylloides, respectively. The in vitro selectivity profile of the antiplasmodial extracts, fractions and compounds versus normal mammalian cells is also reported as an indicator of their toxicity to parasitic but not to mammalian cells at an early stage in a screening procedure for further evaluation in animals. 


\section{Methods}

\section{General experimental procedures}

The methanol and hydroethanol were used as solvents for the extraction of plant material; $n$-hexane, dichloromethane $\left(\mathrm{CH}_{2} \mathrm{Cl}_{2}\right)$, ethyl acetate (EtOAc) and methanol $(\mathrm{MeOH})$ were used as pure or dual mixtures at different polarities for isolation of compounds. The ${ }^{1} \mathrm{H}$ and ${ }^{13} \mathrm{C}$ NMR spectra were registered at $500 \mathrm{MHz}$ and $125 \mathrm{MHz}$, respectively, on Bruker DRX 500 NMR spectrometers (Bruker, Rheinstetten, Germany), with tetramethylsilane as reference, giving the chemical shifts in ppm and the coupling constants in Hertz. Column chromatographies were carried out on 230-400 mesh silica gel (Merck, Darmstadt, Germany), 70-230 mesh silica gel (Merck, Darmstadt, Germany) and sephadex LH-20 (Sigma-Aldrich, Munich, Germany). Precoated plates of silica gel 60 F254 (Merck; Darmstadt, Germany) were used for analytical purposes and the spots were detected with a UV lamp at 254 and $366 \mathrm{~nm}$ and by spraying with $50 \%$ $\mathrm{H}_{2} \mathrm{SO}_{4}$ followed by heating.

\section{Plant material}

The stem barks of E. calophylloides Benth. and H. afzelii (Oliv.) Harms were collected in the Center Region of Cameroon at Mbalmayo and Mount Kala, respectively and identified by Mr. Nana Victor, a retired botanist at the National Herbarium of Cameroon. The voucher specimens were kept under the reference numbers 29, 528 /HNC and 45,345/HNC for E. calophylloides and $H$. afzelii, respectively.

\section{Parasite strains and cell lines}

The in vitro antiplasmodial assay was performed using the chloroquine-sensitive 3D7 (MRA-102) and multiresistant Dd2 (MRA-150) strains of P. falciparum obtained from Bei Resources (https://www.beiresources. org/). The cytotoxicity assay was performed using the African green monkey normal kidney Vero cells (ATCC CRL 1586) and murine macrophages Raw 264.7 cells (ATCC \#TIB-71) obtained from the American Type Culture Collection (ATCC).

\section{Plant extraction and bio-guided fractionation}

The plant samples were air-dried and ground into fine powder using an electric mill (Hammer Mill, Leabon 9FQ, Zhengzhou, PRC). The resulting powders $(1.2 \mathrm{~kg}$, H. afzelii; $3.0 \mathrm{~kg}$, E. calophylloides) were extracted each by maceration three times at room temperature in a mixture of $\mathrm{EtOH} / \mathrm{H}_{2} \mathrm{O}(7: 3)$ and in methanol, respectively for $72 \mathrm{~h}$. The resulting solutions were filtered, evaporated under vacuum and lyophilized in a freeze-dryer Alpha 2-4 LD plus (Christ, Germany) to yield four extracts viz. the hydroethanolic $(234 \mathrm{~g})$ and methanolic (150 g) extracts of $H$. afzelii and the hydroethanolic
(222) and methanolic (246 g) extract of E. calophylloides. The yields of the large-scale extraction were calculated relative to the weight of the starting plant materials. The extracts were subjected to preliminary antiplasmodial screening and subsequently, bioassay-guided fractionation was performed with the affordable extracts.

Part of the hydroethanolic active crude extract (232.5 g) from stem bark of $H$. afzelii was subjected to vacuum liquid chromatography and successively eluted with $\mathrm{CH}_{2} \mathrm{Cl}_{2}$, EtOAc, mixtures of EtOAc/MeOH of increasing polarities and $\mathrm{MeOH}$, leading to five fractions coded: F1 (0.8 g, $\left.\mathrm{CH}_{2} \mathrm{Cl}_{2}\right) ; \mathrm{F} 2$ (15.0 g, EtOAc); F3 [15.6 g, EtOAc/ $\mathrm{MeOH}$ (75:25), v/v]; F4 [36.1 g, EtOAc/MeOH (50:50), $\mathrm{v} / \mathrm{v}$ ] and F5 (39.8 g, MeOH). Among the promising fractions, F4 was afforded in higher quantity and demonstrated high antiplasmodial activity and higher selectivity (Table 2). Therefore, $35 \mathrm{~g}$ of F4 was further submitted to silica gel column chromatography using a stepwise gradient of EtOAc in $n$-hexane, then pure ethyl acetate followed by a gradient of $\mathrm{MeOH}$ in EtOAc to yield compounds 1 (45.1 mg, Hex/EtOAc 60:40, v/v), 2 (10.2 mg, Hex/EtOAc 50:50, v/v), 3 (11.1 mg, Hexane/EtOAc 40: 60, v/v), 4 (10.6 mg, Hexane/EtOAc 50:50, v/v) and, 5 (17.3 mg, Hexane/EtOAc 95: 5, v / v) (Fig. 1).

Portion of the methanolic active crude extract (244.9 g) from the stem bark of E. calophylloides was subjected to a vacuum liquid chromatography and successively eluted with hexane, mixtures of Hex/EtOAc and EtOAc/ $\mathrm{MeOH}$ of rising polarities and $\mathrm{MeOH}$, leading to five fractions: F6 [16.5 g, Hex/EtOAc (75:25), v/v]; F7 [9.2 g, Hex/EtOAc (50:50-25:75), v/v]; F8 (26.6 g, EtOAc); F9 [110.1 g, EtOAc/MeOH (75:25), v/v] and F10 (39.6 g, $\mathrm{MeOH}) .25 \mathrm{~g}$ each of fractions F8 and F9 which demonstrated the best antiplasmodial activities (Table 2) were subjected to purification on an open column chromatography and eluted successively with a gradient of EtOAc in Hex and $\mathrm{MeOH}$ in EtOAc to afford compounds 6 (54.4 mg, Hex / EtOAc 30:70, v/v) and 7 (9.5 mg, EtOAc) from fraction F8, and compound 8 (15.0 mg, Hexane / EtOAC 20:80, v/v) from fraction F9 (Fig. 2).

\section{Antiplasmodial susceptibility testing Plasmodium falciparum continuous culture and maintenance}

The Chloroquine-sensitive 3D7 (MRA-102) and resistant P. falciparum Dd2 (MRA-150) strains were cultured in fresh $\mathrm{O}^{+}$human red blood cells at 3\% haematocrit in complete RPMI 1640 medium [500 mL RPMI 1640 (Gibco, UK) supplemented with $25 \mathrm{mM}$ HEPES (Gibco, UK), 0.50\% Albumax I (Gibco, USA), 1X hypoxanthine (Gibco, USA) and $20 \mu \mathrm{g} / \mathrm{mL}$ gentamicin (Gibco, China)] and incubating at $37^{\circ} \mathrm{C}$ in a humidified atmosphere with $5 \% \mathrm{CO}_{2}$. The culture medium was renewed daily to propagate the culture. Thin blood smears were made 


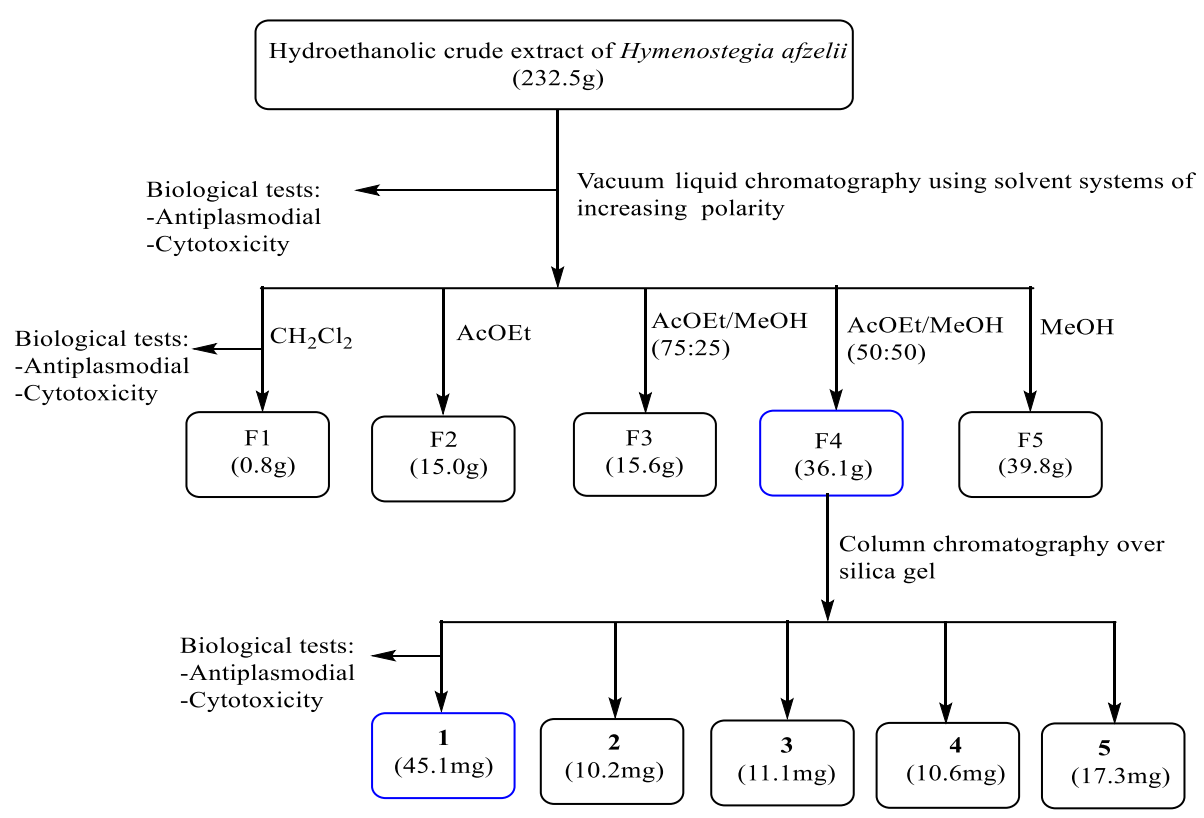

Legend: — Most potent and selective fraction/compound

Fig. 1 Bio-assay guided isolation of active compounds from the hydroethanolic crude extract of the stem bark of H. afzelii

and stained with $10 \%$ Giemsa solution for $10 \mathrm{~min}$ and microscopically examined under oil immersion to monitor cell cycle transition and parasitaemia.

\section{Synchronization of parasite culture}

Before each experiment, synchronized ring stage parasites were obtained by $5 \%$ sorbitol $(\mathrm{w} / \mathrm{v})$ treatment as previously described [19]. The experiment with synchronized ring stage culture provided distinct observing growth inhibitory effect without a rise in parasitemia during the ring-trophozoite-schizont transitions.

\section{SYBR green I fluorescence-based antiplasmodial assay}

The parasite susceptibility was determined in 96-well microtitration plates using the SYBR green I fluorescencebased method [20] with some modifications. Briefly, sorbitol-synchronized ring stage parasites (hematocrit: $1.5 \%$, parasitemia: $1 \%$ ) were incubated in the presence of two-fold diluted extracts $(0.78-100 \mu \mathrm{g} / \mathrm{mL}$, DMSO $0.5 \%)$, fractions $(0.39-50 \mu \mathrm{g} / \mathrm{mL}$, DMSO $0.5 \%)$ or compounds (0.15-20 $\mu \mathrm{g} / \mathrm{mL}$, DMSO 0.5\%). Artemisinin (98\%, SigmaAldrich, Germany) and Chloroquine (98\%, Sigma-Aldrich, Germany) were used as reference compounds at concentration ranges from 7.81-1000 nM. Drug-free culture wells in $0.5 \%$ DMSO were considered as positive growth controls. After $72 \mathrm{~h}$ of incubation, $50 \mu \mathrm{L}$ of SYBR Green I lysis solution [Tris $(20 \mathrm{mM}$; pH 7.5) (Sigma-Aldrich), EDTA (5 mM) (Sigma-Aldrich), saponin (0.008\%, w/v) (Sigma-Aldrich), Triton X-100 (0.08\%, v/v) (Sigma-
Aldrich) and SYBR Green (2x) (Life technologies)] were added to each well and the plate was incubated in the dark at $37^{\circ} \mathrm{C}$ for $30 \mathrm{~min}$. SYBR green I fluorescence was measured using a Fluoroskan Ascent multi-well plate reader (Thermo scientific) with excitation and emission wavelength bands set at 485 and $538 \mathrm{~nm}$, respectively. These data were normalized to percent control activity using Microsoft Excel software and median maximal effective concentrations $\left(\mathrm{EC}_{50} \mathrm{~s}\right)$ calculated using GraphPad Prism 5.0 software (San Diego, California) with data fitted by nonlinear regression to the variable slope sigmoidal doseresponse formula $\mathrm{y}=100 /\left[1+10^{(\log I C 50-x) H}\right]$, where $H$ is the hill coefficient or slope factor [21]. The resistance indices (RI), defined as the ratio of the $\mathrm{EC}_{50}$ of drug-resistant strain to the $\mathrm{EC}_{50}$ of sensitive strain were calculated.

\section{Cytotoxicity study}

The cytotoxicity of active natural products was assessed according to the protocol described by [22]. The African green monkey normal kidney Vero cells (ATCC CRL 1586) and murine macrophages Raw 264.7 cells (ATCC \#TIB-71) were maintained in T-25 flasks (Corning Incorporated, USA) using complete Dulbecco's Modified Eagle's Medium (Sigma-Aldrich, Germany), supplemented with, 10\% Fetal Bovine Serum (Sigma-Aldrich, Germany), $0.2 \%$ sodium bicarbonate (w/v) (Sigma-Aldrich, Germany) and 1\% (v/v) Penicillin-Streptomycin (Sigma-Aldrich, Germany). The cells were kept at $37^{\circ} \mathrm{C}$ for $72 \mathrm{~h}$ in $5 \% \mathrm{CO}_{2}$ incubator, and the medium was 


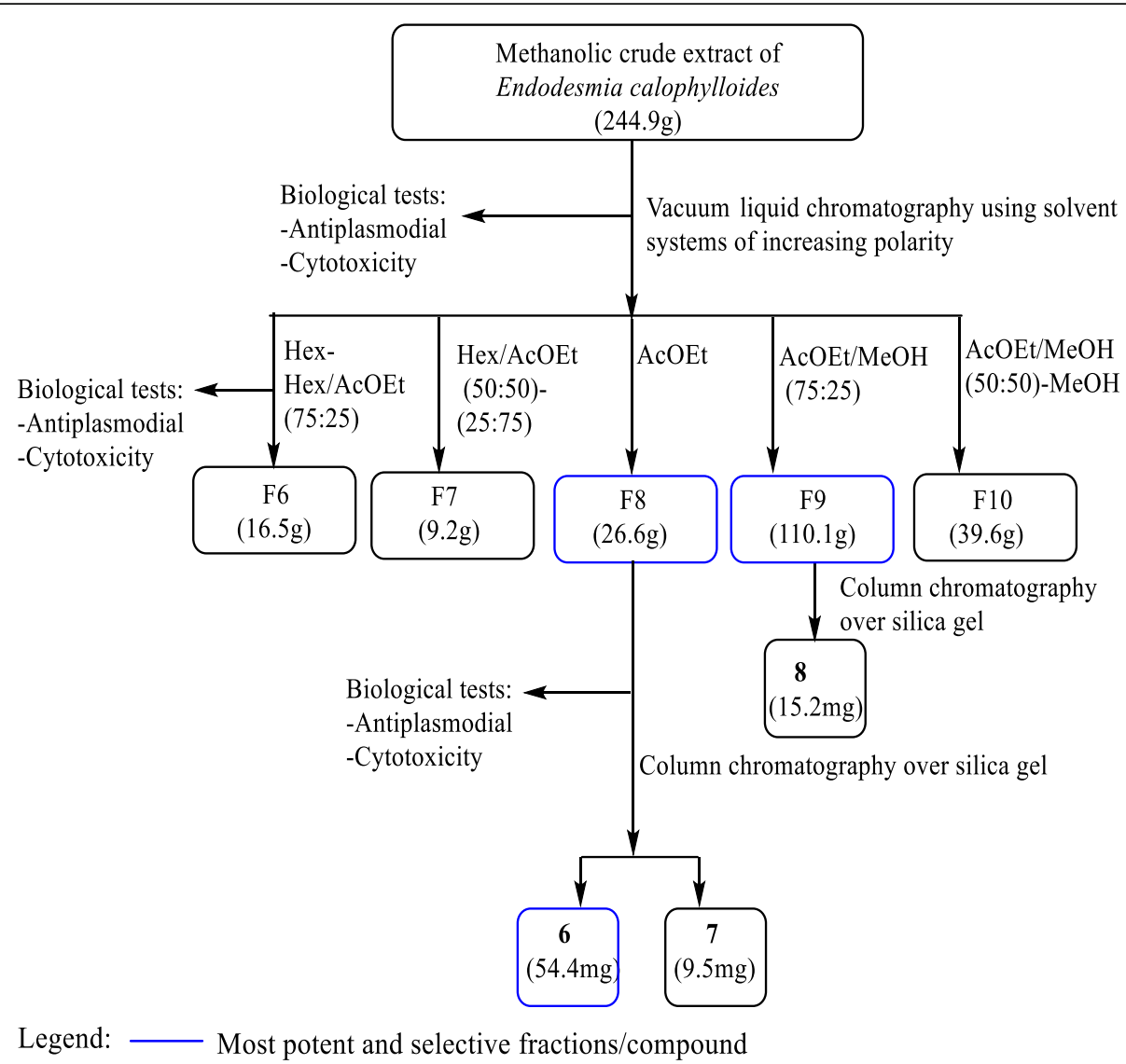

Fig. 2 Bio-assay guided isolation of active compounds from the methanolic crude extract of the stem bark of E. calophylloides

renewed each $72 \mathrm{~h}$ and the cell density monitored under the inverted fluorescent microscope Etaluma 520 (Etaluma, USA) until the formation of a monolayer. Confluent culture (nearly 90\%) was trypsinized (0.05\% Trypsin-EDTA, Sigma-Aldrich, Germany), then centrifuged at $1800 \mathrm{rpm}$ for $5 \mathrm{~min}$ and the resulting pellet was re-suspended in culture medium. Cells at $10^{4}$ cells per well were seeded $(100 \mu \mathrm{L})$ in 96-well culture plates (Costar, USA) and incubated overnight to allow cell adhesion. Thereafter, $10 \mu \mathrm{L}$ of serially diluted extracts, fractions $(\leq 200 \mu \mathrm{g} / \mathrm{mL})$, and compounds $(\leq 50 \mu \mathrm{g} / \mathrm{mL})$ were added to plate wells in duplicate. The plates were incubated in a humidified and $5 \% \mathrm{CO}_{2}$ atmosphere at $37^{\circ} \mathrm{C}$ for $48 \mathrm{~h}$. Podophyllotoxin at $20 \mu \mathrm{M}$ was added as positive control and wells containing untreated cells were included as $100 \%$ growth control. Ten microliters of resazurin stock solution $(0.15 \mathrm{mg} / \mathrm{mL}$ in sterile PBS), were added to each well, and incubated for an additional $4 \mathrm{~h}$. Fluorescence was then read using a Magelan Infinite M200 fluorescence multi-well plate reader (Tecan) with excitation and emission wavelengths at 530 and $590 \mathrm{~nm}$, respectively. The percentage of cell viability was calculated with regard to the negative control, and subsequently used to determine the concentration that reduced $50 \%$ of cell viability $\left(\mathrm{CC}_{50}\right)$ by non-linear regression using the GraphPad Prism software version 5.0 (San Diego, California) as described above. Selectivity indices $\left(\mathrm{SI}=\mathrm{CC}_{50} / \mathrm{EC}_{50}\right.$, defining the balance between cytotoxicity and antiplasmodial activity) were calculated for each test substance.

\section{Data analysis}

All the results represented are mean \pm standard deviation (SD) from two independent experiments. Microsoft Excel Software was used to calculate the percentage of inhibition. The $\mathrm{EC}_{50}$ and $\mathrm{CC}_{50}$ values for the in vitro antiplasmodial activity were determined by non-linear regression analysis using GraphPad Prism 5.0 Software.

\section{Results}

\section{Chemical characterization of the isolated natural compounds}

A total of 8 compounds were isolated of which compounds 3 and 5 were obtained respectively from active fractions of H. afzelii and E. calophylloides (Fig. 3).

The compounds were identified by comparing their NMR and MS data to those of previously reported compounds viz. apigenin (1) [23], afzelechin (2) [24], kaempferol 
<smiles>O=c1cc(-c2ccc(O)cc2)oc2cc(O)cc(O)c12</smiles>

$\operatorname{apigenin}(\mathbf{1})$<smiles>C=C(C)[C@@H]1CC[C@]2(C)CC[C@]3(C)C(CCC4[C@@]5(C)C[C@H](O)[C@@H](O)C(C)(C)C5CC[C@]43C)C12</smiles>

$2 \beta, 3 \beta$-dihydroxylup-20-ene (4)<smiles>Oc1ccc([C@@H]2Oc3cc(O)cc(O)c3C[C@H]2O)cc1</smiles>

afzelechin (2)<smiles>O=c1c(O)c(-c2ccc(O)cc2)oc2cc(O)cc(O)c12</smiles>

kaempferol (3)<smiles>COc1c(O)cc2c(=O)oc3c(OC)c(O)cc4c(=O)oc1c2c34</smiles>

octacosanoic acid (5)

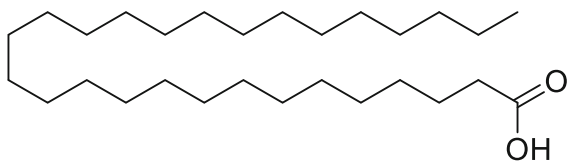

3,3'-O-dimethylellagic acid (6)

Fig. 3 Chemical structures of compounds isolated from active fractions of the stem bark of H. afzelii (1-5) and E. calophylloides (6)

(3) [25], 2 $\beta, 3 \beta$-dihydroxylup-20-ene (4) [26], octacosanoic acid (5) [27] and 3,3'-O-dimethylellagic acid (6) [28]. Compound 6 is reported herein for the first time from $E$. calophylloides, while compounds 7 and 8 were not characterized due to their poor solubility in analytical solvents.

\section{Antiplasmodial activity and cytotoxicity of crude extracts from $H$. afzelii and E. calophylloides}

The methanolic and hydroethanolic crude extracts from $H$. afzelii and E. calophylloides stem barks were assessed for their antiplasmodial activity against Chloroquinesensitive 3D7 and resistant Dd2 strains of $P$. falciparum as well as for cytotoxicity activity against both Vero and Raw cells (Table 1 ).

Extraction yields varied from 07.40 to $19.50 \%$ depending on the plant and the solvent of maceration. The highest extraction yield (19.50\%) was obtained with the hydroethanolic stem bark extract of $H$. afzelii ( $\mathrm{Hasb}^{\mathrm{HE}}$ ) while the extraction yield was lowest $(07.40 \%)$ with the hydroethanolic stem bark extract of E. calophylloides $\left(\mathrm{Ecsb}^{\mathrm{HE}}\right)$ (Table 1).

According to the recommendations of the WHO and previous published criteria, the antiplasmodial activity of natural products is categorized as follows: high $\left(\mathrm{EC}_{50}<\right.$ $5 \mu \mathrm{g} / \mathrm{mL})$, promising $\left(5 \leq \mathrm{EC}_{50}<15 \mu \mathrm{g} / \mathrm{mL}\right)$, moderate $\left(15 \leq \mathrm{EC}_{50}<50 \mu \mathrm{g} / \mathrm{mL}\right)$ and inactive $\left(\mathrm{EC}_{50} \geq 50 \mu \mathrm{g} / \mathrm{mL}\right)$ $[29,30]$. The hydroethanolic extract of the stem bark of H. afzelii $\left(\mathrm{Hasb}^{\mathrm{HE}}\right.$ ) exhibited high antiplasmodial activity against Pf3D7 $\left(\mathrm{EC}_{50}=3.32 \pm 0.15 \mu \mathrm{g} / \mathrm{mL}\right)$ and PfDd2 $\left(\mathrm{EC}_{50}=3.08 \pm 0.21 \mu \mathrm{g} / \mathrm{mL}\right)$. This crude extract was found to be non-cytotoxic against Vero and Raw cell lines at concentrations up to $200 \mu \mathrm{g} / \mathrm{mL}$, with significant selectivity indices $(\mathrm{SI}>60.24$ and $\mathrm{SI}>64.94)$ toward $P$. falciparum 3D7 and Dd2 strains. However, the methanolic extract of the stem bark of $H$. afzelii $\left(\mathrm{Hasb}^{\mathrm{M}}\right)$ was inactive on the assessed Plasmodium strains $\left(\mathrm{EC}_{50}>\right.$ $100 \mu \mathrm{g} / \mathrm{mL}$ ) (Table 1).

Regarding E. calophylloides, both hydroethanolic $\left(\mathrm{Ecsb}^{\mathrm{HE}}\right)$ and methanolic $\left(\mathrm{Ecsb}^{\mathrm{M}}\right)$ stem bark extracts showed promising antiplasmodial profiles on Pf3D7 $\left(\mathrm{EC}_{50} \mathrm{Ecsb}^{\mathrm{HE}}=5.32 \pm 0.03 \mu \mathrm{g} / \mathrm{mL}\right.$ and $\mathrm{EC}_{50} \mathrm{Ecsb}^{\mathrm{M}}=7.40 \pm$ $0.19 \mu \mathrm{g} / \mathrm{mL})$ and PfDd2 $\left(\mathrm{EC}_{50} \mathrm{Ecsb}^{\mathrm{HE}}=8.72 \pm 1.02 \mu \mathrm{g} / \mathrm{mL}\right.$ and $\left.\mathrm{EC}_{50} \mathrm{Ecsb}^{\mathrm{M}}=7.48 \pm 0.07 \mu \mathrm{g} / \mathrm{mL}\right)$. Moreover, both extracts $\left(\mathrm{Ecsb}^{\mathrm{M}}\right.$ and $\left.\mathrm{Ecsb}^{\mathrm{HE}}\right)$ were non-cytotoxic at concentration ranging from 31.72 to $>200 \mu \mathrm{g} / \mathrm{mL}$, but $\mathrm{Ecsb}^{\mathrm{M}}$ presented good selectivity index (from 13.24 to $>27.02$ ) as compared to $\mathrm{Ecsb}^{\mathrm{HE}}$ (from 3.63 to 13.40 ) (Table 1).

Most of the resistance index values were around 1 (Table 1), suggesting equivalent potency against both chloroquine-sensitive and chloroquine-resistant strains of $P$. falciparum. Overall, the antiplasmodial and cytotoxic properties of $\mathrm{Hasb}^{\mathrm{HE}}$ and $\mathrm{Ecsb}^{\mathrm{M}}$ were most advantageous and they were therefore selected for fractionation.

\section{Anti-plasmodial and cytotoxicity profiling of fractions from the promising crude extracts}

The fractionation of the hydroethanolic extract of the stem bark of $H$. afzelii (Hasb ${ }^{\mathrm{HE}}$ ) led to 5 fractions (Fig. 1) of which 3 exhibited antiplasmodial activity ranging from promising to moderate against both chloroquinesensitive 3D7 and resistant Dd2 strains of $P$. falciparum (Table 2). The $25 \%$ ethyl acetate-methanol fraction from $\mathrm{Hasb}^{\mathrm{HE}}$ (F3) showed moderate activity against Pf3D7 


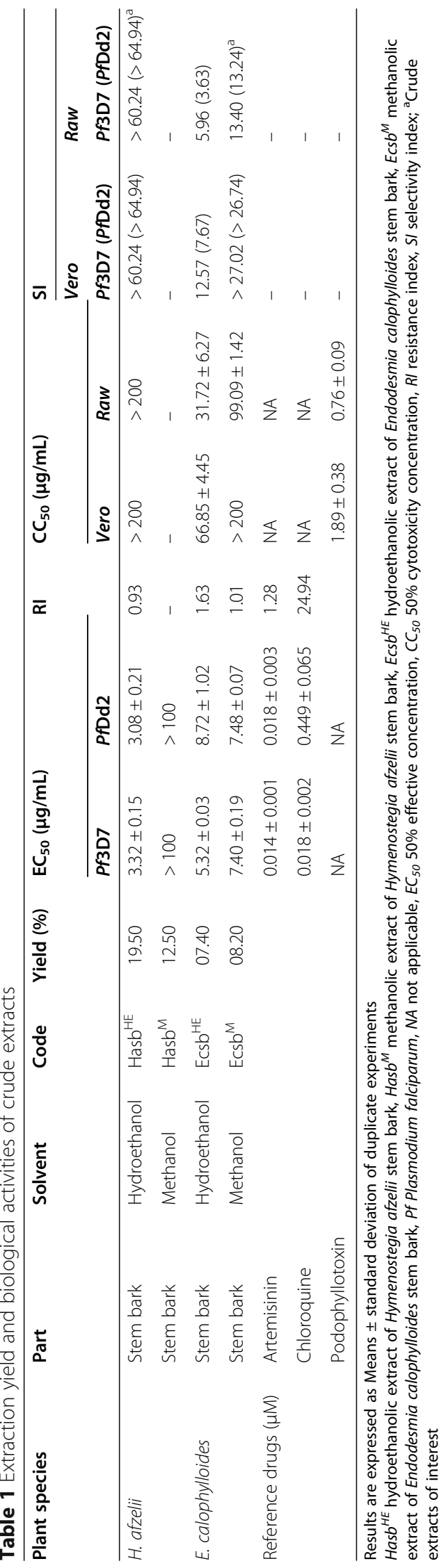




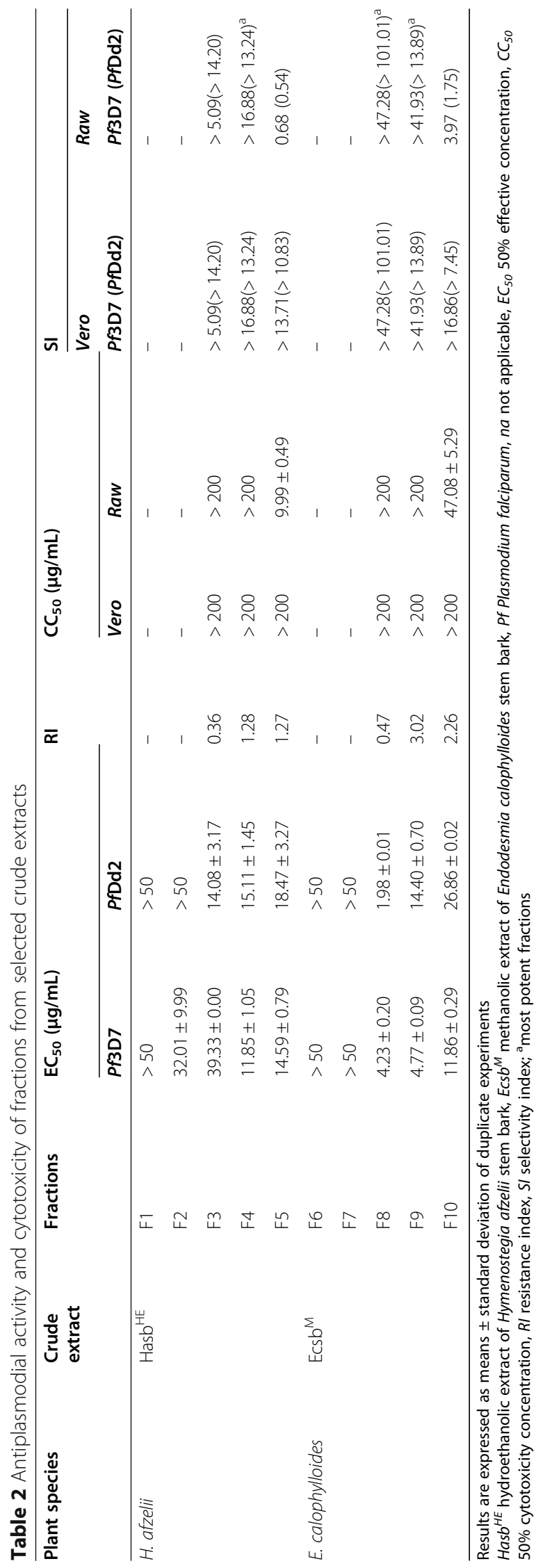


$\left(\mathrm{EC}_{50}=39.33 \pm 0.00 \mu \mathrm{g} / \mathrm{mL}\right)$ and was about 3 -fold more potent on the resistant PfDd2 $\left(\mathrm{EC}_{50}=14.08 \pm 3.17 \mu \mathrm{g} /\right.$ $\mathrm{mL}$ ) with a resistance index of 0.36 . The fraction was non-cytotoxic to Vero and Raw cells at concentrations up to $200 \mu \mathrm{g} / \mathrm{mL}$. The $50 \%$ ethyl acetate-methanol fraction from $\mathrm{Hasb}^{\mathrm{HE}}$ (F4) exerted a promising effect on Pf3D7 $\left(\mathrm{EC}_{50}=11.85 \pm 1.05 \mu \mathrm{g} / \mathrm{mL}\right)$ and a moderate activity on PfDd2 $\left(\mathrm{EC}_{50}=15.11 \pm 1.45 \mu \mathrm{g} / \mathrm{mL}\right)$ with a good selectivity index $\left(\mathrm{SI}_{P f 3 \mathrm{D} 7}>16.88\right.$ and $\left.\mathrm{SI}_{P f \mathrm{Dd} 2}>13.24\right)$. Fractions F3 and F4 displayed similar potency against PfDd2 but F4 was more active against Pf3D7 and presented high selectivity index and higher yield compared to F3. Although the most polar fraction, methanol (F5), exhibited a moderate antiplasmodial activity, it showed unfavorable selectivity $\left(\mathrm{SI}_{P f 3 \mathrm{D} 7}=0.68\right.$ and $\left.\mathrm{SI}_{P f \mathrm{Dd} 2}=0.54\right)$. Moreover, the antiplasmodial activity of this fraction negatively correlated with fractionation of the parent crude extract, suggesting plausible synergistic interaction between the bioactive molecules within the extract as elicitor of the observed activity.

Fractionation of the methanolic crude extract of the stem bark of E. calophylloides (Ecsb ${ }^{\mathrm{M}}$ ) led to 8 fractions that were subsequently pooled based on their thin layer chromatography (TLC) profiles to 5 fractions, F6[HexAcOEt (100:0-75:25)], F7[Hex-AcOEt (50:50-25:75)], F8(AcOEt), F9[AcOEt/MeOH (75:25)] and F10[AcOEt/ $\mathrm{MeOH}$ (50:50-0:100)] (Fig. 2). Three out of the 5 fractions were found to possess antiplasmodial activity (Table 2). The ethyl acetate fraction (F8) presenting high antiplasmodial potency $\left(\mathrm{EC}_{50} P f 3 \mathrm{D} 7=4.23 \pm 0.20 \mu \mathrm{g} / \mathrm{mL}\right.$; $\mathrm{EC}_{50} P f \mathrm{Dd} 2=1.98 \pm 0.01 \mu \mathrm{g} / \mathrm{mL}$ ) also showed no cytotoxicity against both Vero and Raw cells at concentrations up to $200 \mu \mathrm{g} / \mathrm{mL}\left(\mathrm{SI}_{P f 3 \mathrm{D} 7}>47.28 ; \mathrm{SI}_{P f \mathrm{Dd} 2}>101.01\right)$. This fraction strongly inhibited the resistant $\mathrm{Dd} 2$ strain about 2-fold more than the 3D7 chloroquine sensitive strain ( $\mathrm{RI}=0.47$ ). The $25 \%$ ethyl acetate-methanol fraction (F9) demonstrated high activity against Pf3D7 $\left(\mathrm{EC}_{50}=4.77 \pm\right.$ $0.09 \mu \mathrm{g} / \mathrm{mL})$ and promising against PfDd2 $\left(\mathrm{EC}_{50}=\right.$ $14.40 \pm 0.70 \mu \mathrm{g} / \mathrm{mL}$ ) and was found to be non-cytotoxic to mammalian cells at the tested concentration $(200 \mu \mathrm{g} /$ $\mathrm{mL})$. The fraction F10 showed antiplasmodial activity level ranging from promising on Pf3D7 $\left(\mathrm{EC}_{50}=11.86 \pm\right.$ $0.29 \mu \mathrm{g} / \mathrm{mL})$ to moderate on PfDd2 $\quad\left(\mathrm{EC}_{50}=26.86 \pm\right.$ $0.02 \mu \mathrm{g} / \mathrm{mL})$. However, F10 showed poor selectivity on Pf3D7 and PfDd2 with regard to Raw cells $\left(\mathrm{SI}_{P f 3 \mathrm{D} 7}=\right.$ 3.97; $\left.\mathrm{SI}_{P f \mathrm{Dd} 2}=1.75\right)$. In comparison to the crude extract, the fractionation led to significant improvement of the antiplasmodial activity of F8 $\left(\mathrm{Ecsb}^{\mathrm{M}}\right.$ : $\mathrm{EC}_{50}$ Pf3D7 $=7.40 \pm$ $0.19 \mu \mathrm{g} / \mathrm{mL} ; \mathrm{EC}_{50} P f \mathrm{Dd} 2=7.48 \pm 0.07 \mu \mathrm{g} / \mathrm{mL}$ ) whereas the activity of F10 was lower. The activity of F9 was also improved on Pf3D7 but decreased on PfDd2 as compared to the crude extract.

Overall, fractions F4, F8 and F9 showed higher antiplasmodial potency and selectivity. They were therefore selected for further fractionation to isolate the active ingredients.

\section{Anti-plasmodial and cytotoxicity of isolated compounds}

The bioassay guided fractionation based on in vitro antiplasmodial and cytotoxicity tests led to the isolation of several classes of chemical constituents. Table 3 reports the biological parameters of the isolated compounds. The thresholds for the antiplasmodial activity were based on the established criteria [31] where $\mathrm{EC}_{50}<1 \mu \mathrm{M}$ indicates compound with excellent/potent activity; $\mathrm{EC}_{50}$ of 1-20 $\mu \mathrm{M}$, good activity; $\mathrm{EC}_{50}$ of $20-100 \mu \mathrm{M}$, moderate activity; $\mathrm{EC}_{50}$ of $100-200 \mu \mathrm{M}$, low activity; and $\mathrm{EC}_{50}>$ $200 \mu \mathrm{M}$, inactive.

Overall, only compounds 1 and 6 showed antiplasmodial activity with $\mathrm{EC}_{50}$ values of $19.01 \pm 0.72 \mu \mathrm{M}$ and $16.39 \pm 0.52 \mu \mathrm{M}$ for 1 and, $4.27 \pm 0.05 \mu \mathrm{M}$ and $1.36 \pm$ $0.47 \mu \mathrm{M}$ for 6 , respectively against Pf3D7 and PfDd2, and resistance indices less than 1 , indicating more pronounced potency on the resistant strain PfDd2 compared to the sensitive strain. The two compounds were highly selective with SI higher than 9. The antiplasmodial effect of compound 6, identified as 3-3'-O-dimethylellagic acid was 4- and 12-fold higher against Pf3D7 and PfDd2 respectively compared to compound 1, apigenin. More importantly, it was 3-fold more active on chloroquine resistant strain PfDd2 versus chloroquine sensitive strain Pf3D7 of P. falciparum $(\mathrm{RI}=0.32)$.

As far as compound 6 is concerned, fractionation of the patent crude extract led to activity magnification by around 7 and 15 times respectively against Pf3D7 and PfDd2.

\section{Discussion}

The current study aimed at identifying antiplasmodial compounds from the stem bark extracts of $H$. afzelii and E. calophylloides.

The hydroethanolic extract from the stem bark of $H$. afzelii ( $\mathrm{Hasb}^{\mathrm{HE}}$ ) exhibited promising antiplasmodial activity against chloroquine-sensitive $P f 3 D 7$ and multiresistant PfDd2 plasmodial strains while the methanolic extract $\left(\mathrm{Hasb}^{\mathrm{M}}\right)$ showed no activity at up to $100 \mu \mathrm{g} / \mathrm{mL}$ (Table 1). This contrast in antiplasmodial activity might be explained by the compositional differences of the two extracts dragged by different solvents of extraction. To the best of our knowledge, the antiplasmodial activity of the $H$. afzelii plant extracts is being reported here for the first time. Meanwhile, studies carried out on other Caesalpiniaceae species revealed interesting antiplasmodial potencies when extracts are prepared using ethanolic and / or water. In this line, Tona and collaborators [32] reported high in vitro antiplasmodial activity $\left(\mathrm{EC}_{50}<3 \mu \mathrm{g} / \mathrm{ml}\right)$ for the ethanol extract of the leaves of Cassia occidentalis L. Also, the aqueous extract from the 


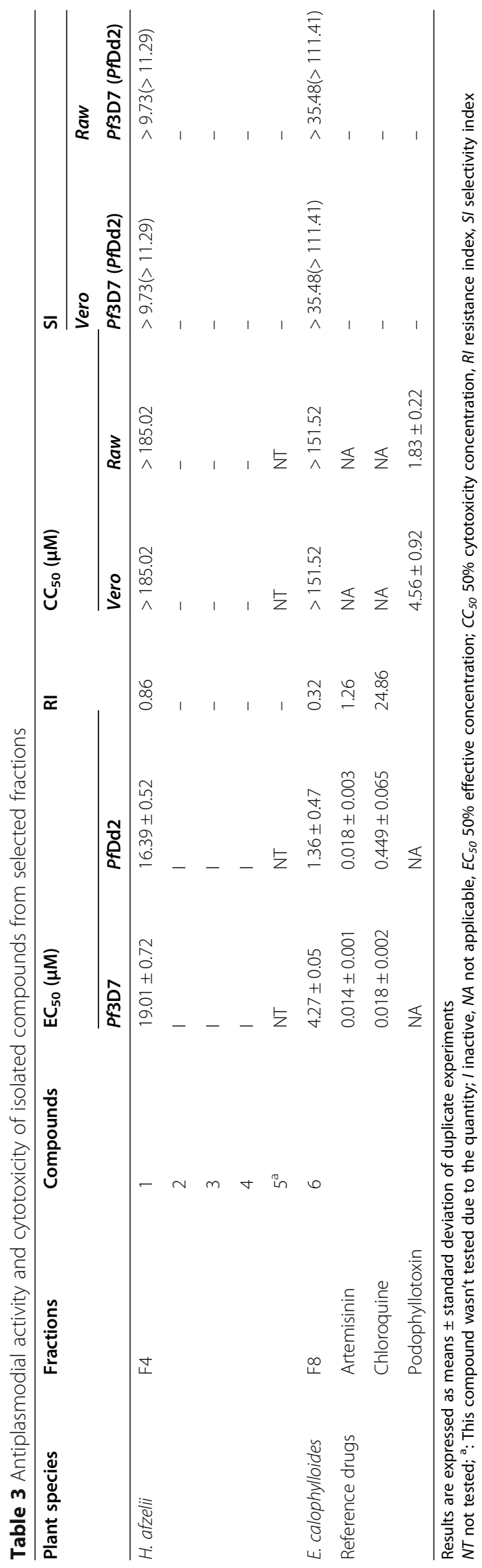


fruit of Tamarindus indica L. showed potent activity against $P$. falciparum clinical isolates $\left(\mathrm{EC}_{50}=2.042 \mu \mathrm{g} / \mathrm{ml}\right)$ [33]. The ethanolic leaves extract from Senna occidentalis L. inhibited the chloroquine-sensitive strain 3D7 and chloroquine-resistant strain INDO of $P$. falciparum with $\mathrm{EC}_{50}$ values of $48.80 \mu \mathrm{g} / \mathrm{ml}$ and $54.28 \mu \mathrm{g} / \mathrm{ml}$, respectively [34]. Interestingly, the highly active hydroethanolic extract of $\mathrm{H}$. afzelii $\left(\mathrm{Hasb}^{\mathrm{HE}}\right)$ corroborated this general trend, and additionally showed no significant cytotoxicity effect towards Vero and Raw cell lines (SI > 60). This further suggests that, $\mathrm{Hasb}^{\mathrm{HE}}$ preferentially inhibited malaria parasites rather than the mammalian cells. Similar trend has previously been reported by Awantu and collaborators [12] while studying the effect of methylene chloridemethanol extracts from leaves and stem bark of $H$. afzelii on anhydrous Artemia salina larvae. Given that this pioneering study has unveiled high antiplasmodial potency of Hasb $^{\mathrm{HE}}$, species from Hymenostegia genus should be extensively explored for the identification of naturally occurring bioactive molecules against malaria parasites.

Endodesmia calophylloides use in traditional medicine for the treatment of malaria is not really documented. However, several species belonging to the Guttiferae family such as Garcinia kola Heckel, Garcinia polyantha Oliv., Cratoxylum cochinchinense (Lour.) Blume, Allanblackia spp. are widely used by traditional healers to cure malaria and related symptoms [32, 35-38]. In this work, we demonstrated that both hydroethanolic $\left(\mathrm{Ecsb}^{\mathrm{HE}}\right)$ and methanolic $\left(\mathrm{Ecsb}^{\mathrm{M}}\right)$ stem bark extracts of $E$. calophylloides exhibited promising antiplasmodial potency against both chloroquine-sensitive Pf3D7 and multi-resistant PfDd2 strains. These results corroborate those of Ngouamegne and collaborators who showed that hexane, ethanol and methanol crude extracts from stem bark of E. calophylloides exhibited potent antiplasmodial activity against the chloroquine-resistant W2 strain of $P$. falciparum with respective $\mathrm{EC}_{50}$ values of $9.3 \pm 1.0 \mu \mathrm{g} / \mathrm{mL} ; 7.4 \pm 0.6 \mu \mathrm{g} / \mathrm{mL}$ and $12.8 \pm 1.0 \mu \mathrm{g} / \mathrm{mL}$ [18]. These results highlighted the potential of E. calophylloides stem bark as source of antiplasmodial natural products with potency against sensitive and resistant strains of $P$. falciparum.

The fractionation of the promising extracts $\left(\mathrm{Hasb}^{\mathrm{HE}}\right.$, $\mathrm{Ecsb}^{\mathrm{M}}$ ) led to various fractions with antiplasmodial activity (F3, F4, F5, F8, F9 and F10) (Table 2), supporting the bio-guided exploration approach. Interestingly, the results showed that fraction F8 (obtained in 100\% ethyl acetate) from $\mathrm{Ecsb}^{\mathrm{M}}$ extract of E. calophylloides was almost 2-fold more active against the multi-resistant Dd2 strain compared to the chloroquine sensitive 3D7 strain of $P$. falciparum (resistance index 0.47). This suggests the possibility of unique and novel drug targets in the resistant strain for active principles.

Compound 1, a flavonoid identified as apigenin, was isolated for the first time from $H$. afzelii stem bark by
Awantu and collaborators [12]. Our findings on the antiplasmodial potency of apigenin corroborated previous reports on this compound. Indeed, Köhler and collaborators reported the antiplasmodial activity of apigenin against chloroquine sensitive $p o W$ and multi-resistant Dd2 strains of $P$. falciparum with $\mathrm{EC}_{50}$ of $19.0 \mu \mathrm{M}$ and $28.5 \mu \mathrm{M}$, respectively [39]. Also, Lehane and Saliba [40] studied some common dietary flavonoids and found that apigenin was among those exhibiting antiplasmodial activity with $\mathrm{EC}_{50}$ values of $20 \pm 3 \mu \mathrm{M}$ against the chloroquine sensitive strain Pf3D7 and $13 \pm 2 \mu \mathrm{M}$ against the chloroquine resistant strain Pf7G8. In the same line, Vitalini and collaborators [41] showed that apigenin inhibited the growth of $P$. falciparum strains with $\mathrm{EC}_{50}$ of $25.4 \pm 7.9 \mu \mathrm{g} / \mathrm{mL}$ for the chloroquine-sensitive strain D10 and $20.2 \pm 6.4 \mu \mathrm{g} / \mathrm{mL}$ against the resistant strain W2. Amiri and collaborators [42] also demonstrated that apigenin significantly suppressed $P$. berghei parasiteamia by $69.74,50.3$, and $49.23 \%$ at concentrations of 70,35 and $15 \mathrm{mg} / \mathrm{kg} /$ day, respectively in a murine malaria model. Muhaimin and collaborators [43] identified apigenin as major constituent in the ethanolic extract of Macaranga gigantea (Rchb. f. \& Zoll.) Müll.Arg. leaf and incriminated it to be responsible for the antiplasmodial activity of this plant species. A phytochemical screening led Phadungrakwittaya [44] to detect high quantity of apigenin in $80 \%$ ethanolic extract of Artemisia annua L. leaf. Indeed, artemisinin which is nowadays the backbone of gold standard drugs for malaria management was isolated from A. annua L. but the identification of other components in high quantity such as apigenin in the species could support the fact that these constituents may play an additional role in the antiplasmodial properties of this plant. Studies on the putative mechanism of action of apigenin revealed that, this flavonoid act by inhibiting $P$. falciparum fatty acid biosynthesis. In fact, Tasdemir and collaborators [45] demonstrated that apigenin inhibits FabI, a crucial enzyme involved in fatty acid biosynthesis of $P$. falciparum with an $\mathrm{EC}_{50}$ of $50 \mu \mathrm{M}$. Comparing the susceptibility of both investigated malaria parasite strains to apigenin (1), it appeared that the multi-resistant strain PfDd2 was more susceptible than the chloroquine sensitive strain 3D7. These results are similar to those obtained by Vitalini and collaborators [41] who reported that apigenin was more potent against choloroquine-resistant strain PfW2 (EC50 of $20.2 \pm 6.4 \mu \mathrm{g} / \mathrm{mL}$ ) as compare to the sensitive strain PfD10 $\left(\mathrm{EC}_{50}\right.$ of $\left.25.4 \pm 7.9 \mu \mathrm{g} / \mathrm{mL}\right)$. Likewise, we noticed the difference in antiplasmodial activity of isolated flavonoids, which was correlated to their chemical structures. Indeed, compound 3 (afzelechin) was inactive against both $P$. falciparum strains and differs from apigenin in that ring $\mathrm{C}$ does not bear a ketone function and a $\mathrm{C}=\mathrm{C}$ unsaturation but has hydroxyl group on carbon 3. Thus, 
the ketone function and the unsaturation could play a favorable role in the antiplasmodial potential of apigenin. Foreseeable explanation could be the fact that the functional composition of ring $\mathrm{C}$ of flavonoids plausibly create a difference in cell permeability of the two molecules. Lehane \& Saliba [40] hypothesized on the probable link between the structural difference of some flavonoids and cell permeability. In addition to the antiplasmodial activity, our findings showed that apigenin did not exhibit significant cytotoxicity effect toward Vero and Raw cell lines. This is in line with previous reports by Amiri and collaborators [42] showing that apigenin had no signs of cytotoxicity on human liver cell line Huh7 as well as membrane disruption on red blood cells. However, Matsuo and collaborators [46] reported a toxic effect of apigenin toward two normal human cells, TIG-1 and HUVE at 50\% lethal concentration $\left(\mathrm{LC}_{50}\right)$ value of $110 \mu \mathrm{M}$. But herein, $\mathrm{EC}_{50}$ of apigenin on both strains of $P$. falciparum are at least 5-fold lower than the $\mathrm{LC}_{50}$ values reported against both human cell lines insinuating that this compound remained selectively more toxic to the parasite than the mammalian cell lines.

Compound 6, 3,3'-O-dimethylellagic acid, exhibited a better antiplasmodial effect than compound 1 (apigenin) against both $P$. falciparum parasite strains and did not show significant signs of cytotoxicity. This is the first report of the antiplasmodial activity and cytotoxicity of 3 , 3' -O-dimethylellagic acid. However, 3,3'-O-dimethylellagic acid is a derivative of ellagic acid, a class of polyphenols well known for their antiplasmodial properties. In fact, ellagic acid and its derivatives were reported by several authors to display in vitro as well as in vivo antiplasmodial activities without toxicity [47-51]. Preliminary pharmacological target deconvolution and mechanism of action of ellagic acid and its derivatives on P. falciparum suggested that they act at the mature trophozoite and young schizont stages of the erythrocytic cycle of $P$. falciparum [51]. Furthermore, elaborated scientific reports have previously stated that ellagic acid derivatives could act by reducing the glutathione content and by inhibiting $\beta$-hematin formation inside the Plasmodium parasite $[52,53]$, leading to parasite death. Interestingly, we found that 3,3'-O-dimethylellagic acid was at least 7 to 15 times more active than the crude extract against Pf3D7 and PfDd2 respectively, validating the bio-guided approach adopted in this study. The structure-activityrelationship investigation by Sturm and collaborators [54] indicated that the number of hydroxyl groups in the ellagic acid scaffold positively correlated with the antiplasmodial activity. Indeed, authors demonstrated that two derivatives, flavellagic acid and coruleoellagic acid, obtained respectively by introducing one and two hydroxyl groups into ellagic acid polyaromatic ring system, led to more potency compared to ellagic acid. Our finding is consistent with the results of these authors given that 3,3'-O-dimethylellagic acid, bearing 2 times less hydroxyl groups than ellagic acid, exhibited lower potency against the same $P$. falciparum strains $(P f 3 D 7=$ $4.27 \mu \mathrm{M} ; P f \mathrm{Dd} 2=1.36 \mu \mathrm{M})$ compared to the ellagic acid $($ Pf3D7 $=0.819 \mu \mathrm{M} ;$ PfDd2 $=0.351 \mu \mathrm{M})$.

\section{Conclusion}

The bio-guided investigation of extracts from E. calophylloides and $H$. afzelii led to the isolation and identification of two known natural compounds as main antiplasmodial constituents. The antiplasmodial activity of compound 6, 3,3'-O-dimethylellagic acid, obtained from the methanolic extract of stem bark of $E$. calophylloides is herein reported for the first time. This compound exhibited higher bioactivity than compound 1, apigenin, isolated from the hydroethanolic extract of the stem bark of $H$. afzelii. Interestingly, both natural products were not cytotoxic on the tested mammalian cell lines at concentrations far above the median effective concentrations. The results achieved in this study support further safety profiling of the investigated plant species for their ultimate use in folk medicine as remedy against malaria. Likewise, compounds 1 and 6 have suitable bioactivity profiles, and could serve as starting points for hit optimization and hit-to-lead studies in an antimalarial drug discovery program.

\section{Abbreviations}

13C NMR: Carbon-13 nuclear magnetic resonance; 1H NMR: Proton nuclear magnetic resonance; ACTs: Artemisinin-based combination therapies;

ATCC: American type culture collection; $\mathrm{C}=\mathrm{C}$ : Carbon carbon double bonds; $\mathrm{CC}_{50}$ : 50\% Cell cytotoxic concentration; $\mathrm{CH}_{2} \mathrm{Cl} 2$ : Methylene chloride; DMSO: Dimethyl sulfoxide; E. calophylloides: Endodesmia calophylloides; $\mathrm{EC}_{50}: 50 \%$ Effective concentration; Ecsb ${ }^{\mathrm{HE}}$. Hydroethanolic extract of Endodesmia calophylloides stem bark; Ecsb ${ }^{\mathrm{M}}$ : Methanolic extract of Endodesmia calophylloides stem bark; EDTA: Ethylene diamine tetra acetate; EtOAc: Ethyl acetate; EtOH: Ethanol; F: Fraction; H. afzelii: Hymenostegia afzelii; H2O: Water; H2SO4: Sulfuric acid; Hasb ${ }^{H E}$. Hydroethanolic extract of Hymenostegia afzelii stem bark; Hasb ${ }^{\mathrm{M}}$ : Methanolic extract of Hymenostegia afzelii stem bark; HEPE S: 2-[4-(2 hydroxyethyl)piperazin-1-yl]ethanesulfonic acid; Hex: Hexane; HNC: "Herbier National du Cameroun"; I: Inactive; LC 50 : 50\% Lethal concentration; MeOH: Methanol; MHz: Mega Hertz; MS: Mass spectrometry; NA: Not applicable; NMR: Nuclear magnetic resonance spectroscopy; NT: Not tested; RI: Resistance index; RPMI: Roswell Park Memorial Institute Medium; SI: Selectivity index; UV: Ultra violet; WHO: World Health Organization

\section{Supplementary Information}

The online version contains supplementary material available at https://doi. org/10.1186/s12906-021-03352-9.

Additional file 1. 1. NMR data of apigenin (1). 2. NMR data of afzelechin (2). 3. NMR data of kaempferol (3). 4. NMR data of $2 \beta, 3 \beta$-dihydroxylup-20ene (4). 5. NMR data of octacosanoic acid (5). 6. NMR data of 3,3'-Odimethylellagic acid (6).

\section{Acknowledgements}

The authors are grateful to the Cameroon National Herbarium through Mr. Victor Nana for the collection and identification of the plant materials; and to Bei Resources (www.beiresources.org) for the provision of the plasmodial strains. 


\section{Authors' contributions}

FFB and BLN designed and supervised the work; RK performed the In vitro antiplasmodial susceptibility testing, analyzed and interpreted the results; JGK carried out the isolation and structural elucidation of compounds; RK and JGK drafted the manuscript; DD performed the cytotoxicity tests; LA, PVTF, JT and FFB revised the manuscript; FFB and LA supervised the biological part of the work; BLN, NS and BN supervised the chemical part of the work. All authors read and approved the final manuscript version.

\section{Funding}

Consumables and equipment for this study were provided by the YaoundéBielefeld Bilateral Graduate School of Natural Products with Anti-parasitic and Anti-bacterial activities (YaBiNaPA), project Nº57316173 funded by the German Academic Exchange Service (DAAD), the Federal Republic of Germany.

\section{Availability of data and materials}

All data generated or analyzed during this study are included in this published article and its Additional files.

\section{Declarations}

\section{Ethics approval and consent to participate}

Not applicable.

\section{Consent for publication}

Not applicable.

\section{Competing interests}

The authors declare that they have no competing interests.

\section{Author details}

${ }^{1}$ Antimicrobial and Biocontrol Agents Unit (AmBcAU), Laboratory for Phytobiochemistry and Medicinal Plants Studies, Department of Biochemistry, Faculty of Science, University of Yaoundé I, P.O. Box 812, Yaoundé, Cameroon. ${ }^{2}$ Malaria Research Unit, Centre Pasteur du Cameroun, P.O. Box 1274, Yaoundé, Cameroon. ${ }^{3}$ Higher Teachers Training College, University of Yaoundé I, P.O Box 47, Yaounde, Cameroon. ${ }^{4}$ Organic and Bioorganic Chemistry, Faculty of Chemistry, Bielefeld University, D-33501 Bielefeld, Germany. ${ }^{5}$ Laboratory of Pharmacognosy and Pharmaceutical Chemistry, Faculty of Medicine and Biomedical Sciences, University of Yaounde I, P.O Box 1364, Yaounde, Cameroon.

\section{Received: 11 September 2020 Accepted: 11 June 2021}

Published online: 29 June 2021

\section{References}

1. WHO. World malaria report 2019. Geneva: Global Malaria Programme; 2019.

2. Wongsrichanalai C, Pickard AL, Wernsdorfer WH, Meshnick SR. Epidemiology of drug-resistant malaria. Lancet Infect Dis. 2002;2(4):209-18. https://doi. org/10.1016/S1473-3099(02)00239-6.

3. Faurant C. From bark to weed: the history of artemisinin. Parasite. 2011; 18(3):215-8. https://doi.org/10.1051/parasite/2011183215.

4. Kwansa-Bentum B, Agyeman K, Larbi-Akor J, Anyigba C, Appiah-Opong R. In vitro assessment of antiplasmodial activity and cytotoxicity of Polyalthia longifolia leaf extracts on Plasmodium falciparum strain NF54. Malaria Res Treat. 2019;2019:1-9. https://doi.org/10.1155/2019/6976298.

5. Nondo RSO, Moshi MJ, Erasto P, Masimba PJ, Machumi F, Kidukuli AW, et al. Anti-plasmodial activity of Norcaesalpin D and extracts of four medicinal plants used traditionally for treatment of malaria. BMC Complement Altern Med. 2017;17(1):167. https://doi.org/10.1186/s12906-017-1673-8.

6. Hay SI, Guerra CA, Tatem AJ, Noor AM, Snow RW. The global distribution and population at risk of malaria: past, present, and future. Lancet Infect Dis. 2004;4(6):327-36. https://doi.org/10.1016/S1473-3099(04)01043-6.

7. WHO. Status report on artemisinin resistance. Geneva: Global Malaria Programme; 2014

8. Okaiyeto K, Okoh Al. In vitro assessment of antiplasmodial and antitrypanosomal activities of chloroform, ethyl acetate and ethanol leaf extracts of Oedera genistifolia. Appl Sci. 2020;10(19):6987. https://doi.org/1 0.3390/app10196987.
9. Meshnick SR, Dobson MJ. The history of antimalarial drugs. In: Antimalarial chemotherapy. New Jersey: Humana Press; 2001. p. 15-25. https://doi.org/1 0.1385/1-59259-111-6:15.

10. Singh N, Kaushik NK, Mohanakrishnan D, Tiwari SK, Sahal D. Antiplasmodial activity of medicinal plants from Chhotanagpur plateau, Jharkhand, India. J Ethnopharmacol. 2015;165:152-62. https://doi.org/10.1016/j.jep.2015.02.038.

11. Agyare C, Mensah AY, Sarpong K, Komlaga G. Antimicrobial activity of Hymenostegia afzelii and Napoleanea vogelii. Boletín Latinoamericano y del Caribe de Plantas Medicinales y Aromáticas. 2006;5:11-4.

12. Awantu AF, Lenta BN, Donfack EV, Wansi JD, Neumann B, Stammler H-G, et al. Flavonoids and other constituents of Hymenostegia afzelii (Caesalpiniaceae). Phytochem Lett. 2011;4(3):315-9. https://doi.org/10.1016/j. phytol.2011.06.002.

13. Hutchinson LL, Dalziel JM. Flora of west tropical Africa. 2nd ed. London: Oxford University Press; 1954.

14. Odugbemi T. A textbook of medicinal plants from Nigeria. Ed. T. Odugbemi. Unilag, Akoka, Yaba-Lagos: University of Lagos Press; 2008.

15. Irvine FR. Woody plants of Ghana. London: Oxford University Press; 1961

16. Hutchinson LL, Dalziel JM. Flora of West Tropical Africa. London: Oxford University Press; 1954. p. 286-7.

17. Talontsi FM, Islam MT, Facey P, Douanla-Meli C, von Tiedemann A, Laatsch $\mathrm{H}$. Depsidones and other constituents from Phomopsis sp. CAFT69 and its host plant Endodesmia calophylloides with potent inhibitory effect on motility of zoospores of grapevine pathogen Plasmopara viticola. Phytochem Lett. 2012;5(3):657-64. https://doi.org/1 0.1016/j.phytol.2012.06.017.

18. Ngouamegne ET, Fongang RS, Ngouela S, Boyom FF, Rohmer M, Tsamo E, et al. Endodesmiadiol, a friedelane triterpenoid, and other antiplasmodial compounds from Endodesmia calophylloides. Chem Pharm Bull. 2008;56(3): 374-7. https://doi.org/10.1248/cpb.56.374.

19. Lambros C, Vanderberg JP. Synchronization of Plasmodium falciparum erythrocytic stages in culture. J Parasitol. 1979;65(3):418-20. https://doi.org/1 $0.2307 / 3280287$

20. Smilkstein M, Sriwilaijaroen N, Kelly JX, Wilairat P, Riscoe M. Simple and inexpensive fluorescence-based technique for high-throughput antimalarial drug screening. Antimicrob Agents Chemother. 2004;48(5):1803-6. https:// doi.org/10.1128/AAC.48.5.1803-1806.2004.

21. Singh A, Rosenthal PJ. Comparison of efficacies of cysteine protease inhibitors against five strains of Plasmodium falciparum. Antimicrob Agents Chemother. 2001;45(3):949-51. https://doi.org/10.1128/AAC.45.3. 949-951.2001.

22. Mosmann T. Rapid colorimetric assay for cellular growth and survival: application to proliferation and cytotoxicity assays. J Immunol Methods. 1983:65(1-2):55-63. https://doi.org/10.1016/0022-1759(83)90303-4.

23. van Loo P, De Bruyn A. Reinvestigation of the structural assignment of signals in the1H and13C NMR spectra of the flavone apigenin. Magn Reson Chem. 1986:24:879-82.

24. Saijyo J, Suzuki Y, Okuno Y, Yamaki H, Suzuki T, Miyazawa M. a-Glucosidase Inhibitor from Bergenia ligulata. J Olea Sci. 2008;57(8):431-5. https://doi. org/10.5650/jos.57.431

25. Lin L, Huang $X, L v Z$. Isolation and identification of flavonoids components from Pteris vittata L. SpringerPlus. 2016;5(1):1649. https://doi.org/10.1186/s4 0064-016-3308-9.

26. Huang J, Guo Z, Cheng P, Sun B, Gao H-Y. Three new triterpenoids from Salacia hainanensis Chun et how showed effective anti-a-glucosidase activity. Phytochem Lett. 2012;5(3):432-7. https://doi.org/10.1016/j.phytol.2 012.03.016.

27. Joshi $H$, Joshi $A B$, Sati $H, M p G$, Shetty PR, Subrahmanyam $E$, et al. Fatty acids from Memecylon umbellatum (Burm.). Asian J Res Chem. 2009:2:178-80.

28. Khac DD, Tran-Van S, Campos AM, Lallemand J-Y, Fetizon M. Ellagic compounds from Diplopanax stachyanthus. Phytochemistry. 1990;29(1):2516. https://doi.org/10.1016/0031-9422(90)89044-A.

29. Jonville MC, Kodja H, Humeau L, Fournel J, De Mol P, Cao M, et al. Screening of medicinal plants from Reunion Island for antimalarial and cytotoxic activity. J Ethnopharmacol. 2008;120(3):382-6. https://doi.org/10.1 016/j.jep.2008.09.005

30. Lekana-Douki JB, Liabagui SLO, Bongui JB, Zatra R, Lebibi J, Toure-Ndouo FS. In vitro antiplasmodial activity of crude extracts of Tetrapleura tetraptera and Copaifera religiosa. BMC Res Notes. 2011;4(1):506. https://doi.org/10.1186/1 756-0500-4-506 
31. Batista R, De Jesus Silva Júnior A, De Oliveira A Plant-derived antimalarial agents: new leads and efficient phytomedicines Part II Non-alkaloidal natural products Molecules 2009;14:3037-3072, 8, doi: https://doi.org/10.33 90/molecules14083037

32. Tona L, Cimanga RK, Mesia K, Musuamba CT, Bruyne TD, Apers S, et al. In vitro antiplasmodial activity of extracts and fractions from seven medicinal plants used in the Democratic Republic of Congo. J Ethnopharmacol. 2004; 93(1):27-32. https://doi.org/10.1016/j.jep.2004.02.022.

33. Koudouvo K, Karou SD, Ilboudo DP, Kokou K, Essien K, Aklikokou K, et al. In vitro antiplasmodial activity of crude extracts from Togolese medicinal plants. Asian Pac J Trop Med. 2011;4(2):129-32. https://doi.org/10.1016/S1 995-7645(11)60052-7.

34. Murugan K, Aarthi N, Kovendan K, Panneerselvam C, Chandramohan B, Kumar PM, et al. Mosquitocidal and antiplasmodial activity of Senna occidentalis (Cassiae) and Ocimum basilicum (Lamiaceae) from Maruthamalai hills against Anopheles stephensi and Plasmodium falciparum. Parasitol Res. 2015;114(10):3657-64. https://doi.org/10.1007/s00436-015-4593-x.

35. Azebaze A, Teinkela J, Nguemfo E, Valentin A, Dongmo A, Vardamides J. Antiplasmodial activity of some phenolic compounds from Cameroonians Allanblackia. Afr Health Sci. 2015;15(3):835-40. https://doi. org/10.4314/ahs.v15i3.18.

36. Juanda D, Fidrianny I, Ruslan K, Insanu M. Overview of phytochemical compounds and pharmacology activities of Cratoxylum genus. Rasayan J Chem. 2019;12(04):2065-73. https://doi.org/10.31788/RJC.201 9.1245303.

37. Lannang AM, Louh GN, Lontsi D, Specht S, Sarite SR, Flörke U, et al. Antimalarial compounds from the root bark of Garcinia polyantha Olv. J Antibiotics. 2008;61(8):518-23. https://doi.org/10.1038/ja.2008.70.

38. Okolie NJC, Awoibi K. Toxicological and antiplasmodial activities of ethanolic extracts of mango (Mangifera indica) leaves and bitter Cola (Garcinia kola) seeds in albino rats. Int J Sci Res. 2019;8:1777-81.

39. Köhler I, Jenett-Siems K, Siems K, Hernández MA, Ibarra RA, Berendsohn WG, et al. In vitro antiplasmodial investigation of medicinal plants from El Salvador §. Zeitschrift für Naturforschung C. 2002;57(3-4):277-81. https://doi. org/10.1515/znc-2002-3-413.

40. Lehane AM, Saliba KJ. Common dietary flavonoids inhibit the growth of the intraerythrocytic malaria parasite. BMC Res Notes. 2008;1(1):26. https://doi. org/10.1186/1756-0500-1-26.

41. Vitalini S, Beretta G, Iriti M, Orsenigo S, Basilico N, Dall'Acqua S, et al. Phenolic compounds from Achillea millefolium L. and their bioactivity. Acta Biochimica Polonica. 2011;58. doi:https://doi.org/10.18388/abp.2011_2266.

42. Amiri M, Nourian A, Khoshkam M, Ramazani A. Apigenin inhibits growth of the Plasmodium berghei and disrupts some metabolic pathways in mice: in vivo antiplasmodial activity and toxicity mechanism of apigenin. Phytother Res. 2018;32(9):1795-802. https://doi.org/10.1002/ptr.6113.

43. Muhaimin M, Yusnaidar $Y$, Syahri W, Latief M, Dwimalida Putri R, Utami A, et al. Antiplasmodial activity of ethanolic extract of Macaranga gigantea leaf and its major constituent. Pharmacognosy J. 2019;11(6):1181-8. https://doi. org/10.5530/pj.2019.11.183

44. Phadungrakwittaya R. Identification of Apigenin and Luteolin in Artemisia annua L. for the quality control. Siriraj Med J. 2019;71(3):240-5. https://doi. org/10.33192/Smj.2019.37.

45. Tasdemir D, Lack G, Brun R, Rüedi P, Scapozza L, Perozzo R. Inhibition of Plasmodium f alciparum fatty acid biosynthesis: evaluation of FabG, FabZ, and Fabl as drug targets for flavonoids. J Med Chem. 2006;49(11):3345-53. https://doi.org/10.1021/jm0600545.

46. Matsuo M, Sasaki N, Saga K, Kaneko T. Cytotoxicity of flavonoids toward cultured normal human cells. Biol Pharm Bull. 2005;28(2):253-9. https://doi. org/10.1248/bpb.28.253.

47. Banzouzi J-T, Prado R, Menan H, Valentin A, Roumestan C, Mallie M, et al. In vitro antiplasmodial activity of extracts of Alchornea cordifolia and identification of an active constituent: ellagic acid. J Ethnopharmacol. 2002; 81(3):399-401. https://doi.org/10.1016/S0378-8741(02)00121-6.

48. Ndjonka D, Bergmann B, Agyare C, Zimbres FM, Lüersen K, Hensel A, et al. In vitro activity of extracts and isolated polyphenols from west African medicinal plants against Plasmodium falciparum. Parasitol Res. 2012;111(2): 827-34. https://doi.org/10.1007/s00436-012-2905-y.

49. Reddy M, Gupta S, Jacob M, Khan S, Ferreira D. Antioxidant, antimalarial and antimicrobial activities of tannin-rich fractions, Ellagitannins and phenolic acids from Punica granatum L. Planta Med. 2007;73(5):461-7. https://doi. org/10.1055/s-2007-967167.
50. Simões-Pires CA, Vargas S, Marston A, loset J-R, Paulo MQ, Matheeussen A et al. Ellagic acid derivatives from Syzygium cumini stem bark: investigation of their antiplasmodial activity. Nat Prod Commun. 2009;4(10):1371-6.

51. Soh PN, Witkowski B, Olagnier D, Nicolau M-L, Garcia-Alvarez M-C, Berry A, et al. In vitro and in vivo properties of ellagic acid in malaria treatment. Antimicrob Agents Chemother. 2009;53(3):1100-6. https://doi.org/10.112 8/AAC.01175-08

52. Dell'Agli M, Parapini S, Basilico N, Verotta L, Taramelli D, Berry C, et al. In vitro studies on the mechanism of action of two compounds with antiplasmodial activity: Ellagic acid and 3,4,5-Trimethoxyphenyl (6ל-OGalloyl)-b-D-glucopyranoside. Planta Med. 2003;69(2):162-4. https://doi.org/1 0.1055/s-2003-37706.

53. Soh NP, Witkowski B, Gales A, Huyghe E, Berry A, Pipy B, et al. Implication of glutathione in the in vitro antiplasmodial mechanism of action of ellagic acid. Plos One. 2012;7:e45906.

54. Sturm N, Hu Y, Zimmermann H, Fritz-Wolf K, Wittlin S, Rahlfs S, et al. Compounds structurally related to ellagic acid show improved antiplasmodial activity. Antimicrob Agents Chemother. 2009;53(2):622-30. https://doi.org/10.1128/AAC.00544-08.

\section{Publisher's Note}

Springer Nature remains neutral with regard to jurisdictional claims in published maps and institutional affiliations.
Ready to submit your research? Choose BMC and benefit from:

- fast, convenient online submission

- thorough peer review by experienced researchers in your field

- rapid publication on acceptance

- support for research data, including large and complex data types

- gold Open Access which fosters wider collaboration and increased citations

- maximum visibility for your research: over $100 \mathrm{M}$ website views per year

At BMC, research is always in progress.

Learn more biomedcentral.com/submissions 